\title{
Balancing adjustment of exhaust duct system using feedback simulation method
}

\author{
Huei-Jiunn Chen ${ }^{\mathrm{a}, *}$, David W.P. Wang ${ }^{\mathrm{a}}$, Sih-Li Chen ${ }^{\mathrm{b}}$ \\ a Department of Air Conditioning and Refrigeration Engineering, National Taipei University of Technology, 30 Wu Chuan 3rd Road, \\ Wu Ku Industrial Park Wu Ku Hsian, Taipei, Taiwan \\ ${ }^{\mathrm{b}}$ Department of Mechanical Engineering, National Taiwan University, Taipei, Taiwan
}

Received 16 July 2005; accepted 12 August 2005

Available online 27 September 2005

\begin{abstract}
Conventional exhaust duct system design methods utilize the maximum load to choose equipment and ignore the actual running process. Therefore, in actual running process, exhaust duct system needs to meet the flow-rate requirements by adjusting the damper angles or the fan speeds. In addition conventional design methods fail to take into account future development and expansion of the exhaust duct system, which is critical to design concerns. In order to remove the disadvantages of conventional designs, feedback simulation method is proposed to simulate the actual running process. An acid gas exhaust system in a TFT-LCD factory is presented in this study. It demonstrates that the new duct simulation method contains a simple computation procedure and takes into account the balancing adjustment. The proposed design not only shortens the design timeframe and prevents human calculation errors, but also reduces the dependence on designer experience.
\end{abstract}

(c) 2005 Elsevier Ltd. All rights reserved.

Keywords: Feedback simulation method; Exhaust duct system

\section{Introduction}

The exhaust duct system is important to control air pollutants in the factory. An optimum air duct system transports the required amount of exhaust air to the specific spaces and meets a satisfactory system pressure balance. It is essential to have a well-designed exhaust system at the production site. Conventional duct design methods [1] cannot achieve a pressure balance system. After construction of factory is complete, system pressure has to be on-site balanced by adjusting the fan speeds and the branch dampers to meet the designed flow rate. However, the pressure balancing procedures

\footnotetext{
* Corresponding author. Tel.: +88622299 3155; fax: +88622299 5573.

E-mail addresses: soundair@ms19.hinet.net, hjiunn.chen@msa. hinet.net (H.-J. Chen).
}

for air distribution systems is rather complicated [2,3]. It usually takes long time to proportional adjust branch dampers until each terminal has the proper air volume. If the factory is expanded or the duct layout is changed, the pressure balance needs to be readjusted in order for the system to reach equilibrium. Therefore, this method of balancing procedures not only costs lots of manpower but also demands much time and money.

Many scholars have devoted to the research on the design of the duct system. Tsal et al. [4,5] introduced a design that eliminates the disadvantages of conventional designs. With its exact mathematical model and iterative method, the duct system is optimized. Meanwhile, it has the advantages of minimum life cycle cost and system pressure balance. Asiedu et al. [6] proposed a genetic algorithm for the duct ventilation system design. Although both designs enable the system to achieve system pressure balance with the life cycle cost 


\begin{tabular}{|c|c|c|c|}
\hline \multicolumn{4}{|c|}{ Nomenclature } \\
\hline$C_{\mathrm{v}}$ & flow coefficient, $\mathrm{Pa}\left(\mathrm{s} / \mathrm{m}^{3}\right)^{1 / 2}$ & $\Delta P$ & friction loss, $\mathrm{Pa}$ \\
\hline$E_{\mathrm{c}}$ & electricity unit price, dollar/kw-h & $\Delta P_{\text {sys }}$ & system friction loss, $\mathrm{Pa}$ \\
\hline$K_{\text {sys }}$ & $\begin{array}{l}\text { system flow conductance coefficient, } \mathrm{m}^{3} / \mathrm{s} / \\
\mathrm{Pa}^{0.5}\end{array}$ & $\Delta P_{T}$ & $\begin{array}{l}\text { the total friction loss and the total dynamic } \\
\text { loss except dampers, } \mathrm{Pa}\end{array}$ \\
\hline $\begin{array}{l}P_{\text {fan }} \\
P_{\text {sys }}\end{array}$ & $\begin{array}{l}\text { fan total pressure, } \mathrm{Pa} \\
\text { system total pressure, } \mathrm{Pa}\end{array}$ & $\Delta P_{D}$ & dynamic loss of damper, $\mathrm{Pa}$ \\
\hline$Q$ & duct airflow, $\mathrm{m}^{3} / \mathrm{s}$ & \multicolumn{2}{|c|}{ Greek symbols } \\
\hline$Q_{\text {fan }}$ & fan airflow rate, $\mathrm{m}^{3} / \mathrm{s}$ & $\eta_{\mathrm{f}}$ & fan efficiency \\
\hline$Q_{\text {sys }}$ & system airflow rate, $\mathrm{m}^{3} / \mathrm{s}$ & $\eta_{\mathrm{e}}$ & motor efficiency \\
\hline & system annual operation hours, h/year & & \\
\hline
\end{tabular}

taken into account, they fail to give method for flexible design and an insight into the actual operating condition during the design stage. Moreover, they cannot conduct the design in case of expansion of the factory or change of duct lay out.

In terms of duct system simulation research, Tsal et al. [7] introduced a method that consists of system condensing, fan operation point and system expansion procedures. Chen et al. [8] provided the 3C method, dividing the duct system design into three major steps: (1) computer-aided design; (2) computer-aided simulation; (3) correction process. The method uses computer-aided simulation to conduct pressure balance. However 3C method still relies heavily on many empirical rules. Therefore, it usually requires many iterative simulations and correction processes to reach the system pressure balance.

This article proposes a feedback simulation method to adjust the system pressure balance based on the simulation and correction results. The feedback simulation method is very similar to the feedback control in dynamic system. The system uses an error signal to adjust the parameter to be corrected as an input next time. The simulation and correction is repeated until the system reaches equilibrium. The advantages of feedback simulation method are to conduct simulation on systems that have completed the design process or the as-built system. The balancing and adjustment procedures for flow requirements spent on-site can be reduced and the energy conservation strategies for the exhaust duct system can also be obtained.

\section{Feedback simulation method}

Conventional simulations adopt the open loop simulation method, as shown in Fig. 1. The method utilizes the one-way forward method. The advantages are fewer steps, simple process, and less time-consuming. The disadvantage is, due to lack of feedback, it only possesses the simulation feature without the correction function. As a result, it is applied to simpler systems. It is not suitable for exhaust duct systems that are more complicated. Thus feedback simulation method, which is suitable for the process exhaust duct system, is demonstrated in this paper. It includes the system simulation and the correction procedure, as shown in Fig. 2.

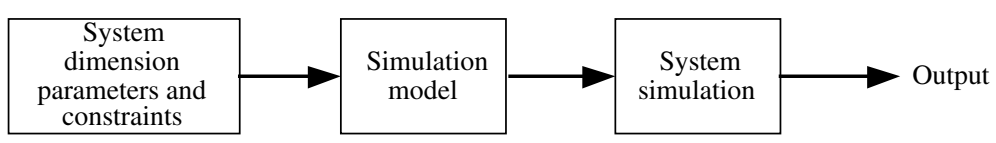

Fig. 1. Open loop simulation.

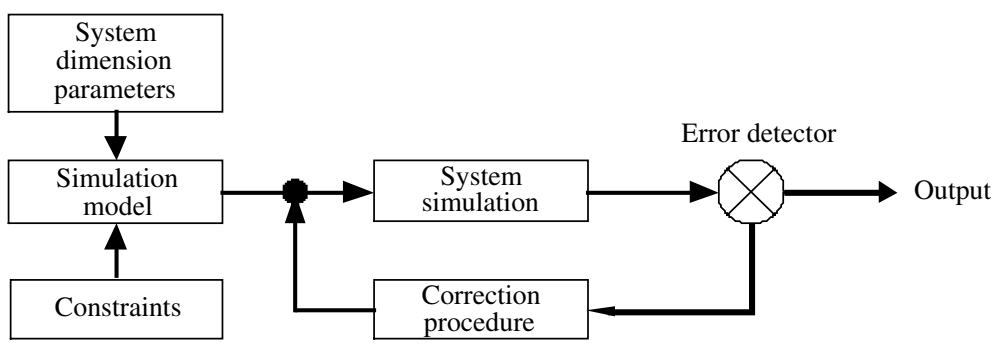

Fig. 2. Feedback simulation method. 


\subsection{System simulation}

The system simulation adopts the simulation method introduced by Tsal et al. [7]. It comprises three major steps - system condensing, fan operating point and system expansion. (a) System condensing: the purpose is to condense a complicated duct system into a virtual duct and obtain the equivalent flow conductance coefficient of a single virtual duct $K_{\text {sys }}$. (b) Fan operating point: when system condensing is completed, the complicated system is simplified to a fan and a single virtual duct. The relationship between the volume flow rate and system friction loss of the system is

$Q_{\text {sys }}=K_{\text {sys }} \sqrt{\Delta P_{\text {sys }}}$

With Eq. (1), the fan operating point can be obtained through the intersection point of the system curve and the fan performance curve. The fan total pressure $P_{\text {fan }}$ and fan volume flow rate $Q_{\text {fan }}$ can be obtained. (c) System expansion: after the fan operating point is determined, system expansion is to restore the condensed system into the original system. Based on various duct's equivalent flow conductance coefficient, the flow rate is distributed to various ducts until the entire system is expanded.

\subsection{Correction procedure}

The most notable feature of the feedback simulation method is the establishment of correction procedures based on the characteristics of the duct system. Suppose there are $N$ paths in an exhaust duct system with the volume flow rates required in the paths being $Q_{1}, Q_{2}, \ldots, Q_{N}$. The total volume flow rate needed by the system is

$Q_{\text {sys }}=\sum_{n=1}^{n=N} Q_{n}$

The total friction loss and the total dynamic loss except dampers for each path are $\Delta P_{T, 1}, \Delta P_{T, 2}, \ldots, \Delta P_{T, N}$, and the dynamic loss created by the dampers in the paths are $\Delta P_{D, 1}, \Delta P_{D, 2}, \ldots, \Delta P_{D, N}$. Then the total friction loss and total dynamic loss of each path is

$\Delta P_{n}=\Delta P_{T, n}+\Delta P_{D, n}, \quad n=1,2, \ldots, N$

The total flow rate provided by the fan must meet the total volume flow rate required by all paths. Therefore, the total volume flow rate provided by the fan is

$Q_{\text {fan }}=Q_{\text {sys }}=\sum_{n=1}^{n=N} Q_{n}$

Since the flow rate provided by the fan is given, the fan operating point can be obtained through the fan performance curve. Through this operating point, the total fan pressure $P_{\text {fan }}$ can be obtained and it should be equal to the total friction loss and total dynamic loss of one path.
$P_{\text {fan }}=\Delta P_{n}$

To meet the pressure balance requirement of all paths, the dynamic loss created by dampers can be obtained as

$\Delta P_{D, n}=P_{\text {fan }}-\Delta P_{T, n}$

Then the flow coefficient created by dampers in various paths can be obtained through Eq. (6)

$C_{\mathrm{v}}=\Delta P_{D, n} / \sqrt{Q_{n}}$

Adjust the flow coefficients of dampers at all paths from Eq. (7) and substitute the corrected values into the system simulation, until the error between the simulated flow rate and the designed flow rate falls within $\pm 5 \%$, the feedback simulation is completed. The results of flow coefficients are converted to the operating angle of the dampers at each path, which provides an efficiency method to meet the system balance.

\section{Case study}

A case study on balancing adjustment of a TFT-LCD exhaust duct system with the developed method is presented. Figs. 3 and 4 show a TFT-LCD acid gas exhaust duct system. There are 18 machines located at the terminal of various paths. Their positions and numbers are shown in Fig. 3. At the first stage of actual running process only 11 machines are operating, while the other 7 machines (M2, M3, M5, M7, M10, M13 and M16) are idling. In the present simulation only 11 paths are considered. Dampers are installed at the terminal of the ducts. They are used to balance and adjust the volume flow rate required by various machines. Their positions and numbers are shown in Fig. 4. The exhaust gas is expelled to the top floor through the scrubber and then is emitted out. The fan performance curve is shown in Fig. 5.

Two different operation strategies, the damper control simulation and fan speed control simulation, are investigated. The simulation parameters are shown in Table 1. They include an air density of $1.2 \mathrm{~kg} / \mathrm{m}^{3}$ and a viscosity coefficient of $1.54 \times 10^{-5} \mathrm{~m}^{2} / \mathrm{s}$. The conduits used in the system are regular galvanized spiral ducts with the absolute roughness being $3 \times 10^{-4} \mathrm{~m}$. The upper and lower velocity limits are $15 \mathrm{~m} / \mathrm{s}$ and $7.5 \mathrm{~m} / \mathrm{s}$, respectively. After giving the duct's diameter and length, system configuration, and fan performance curve, system simulation begins. If the error between the simulated value and the designed value is greater than $\pm 5 \%$, an error signal is returned automatically. The correction procedure will initiate. The feedback simulation will be repeated until the error is smaller than $\pm 5 \%$.

\subsection{Damper control}

Table 2 shows the total friction and dynamic loss at each path. It also shows the dynamic loss from 


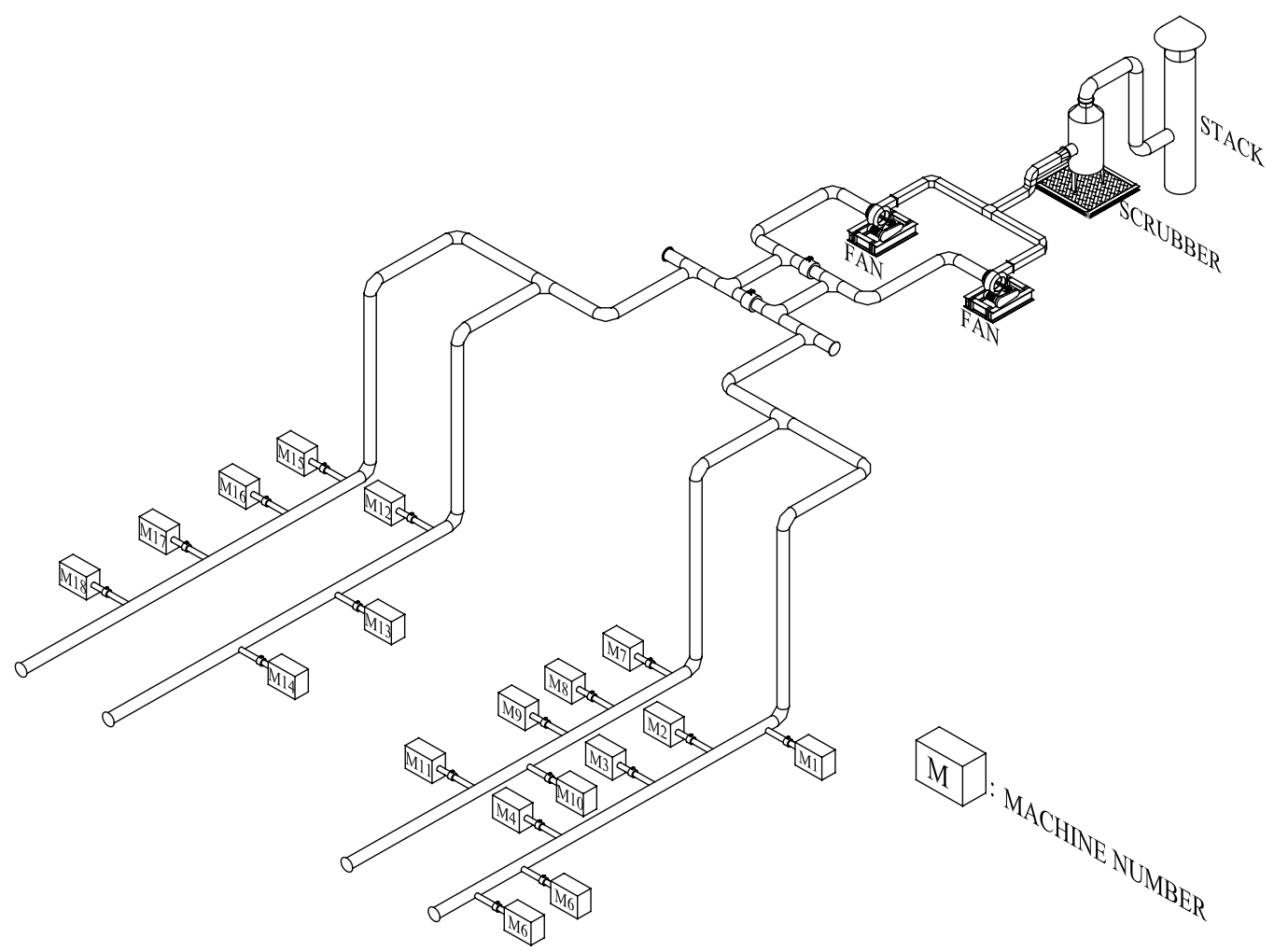

Fig. 3. Machine position of exhaust duct system.

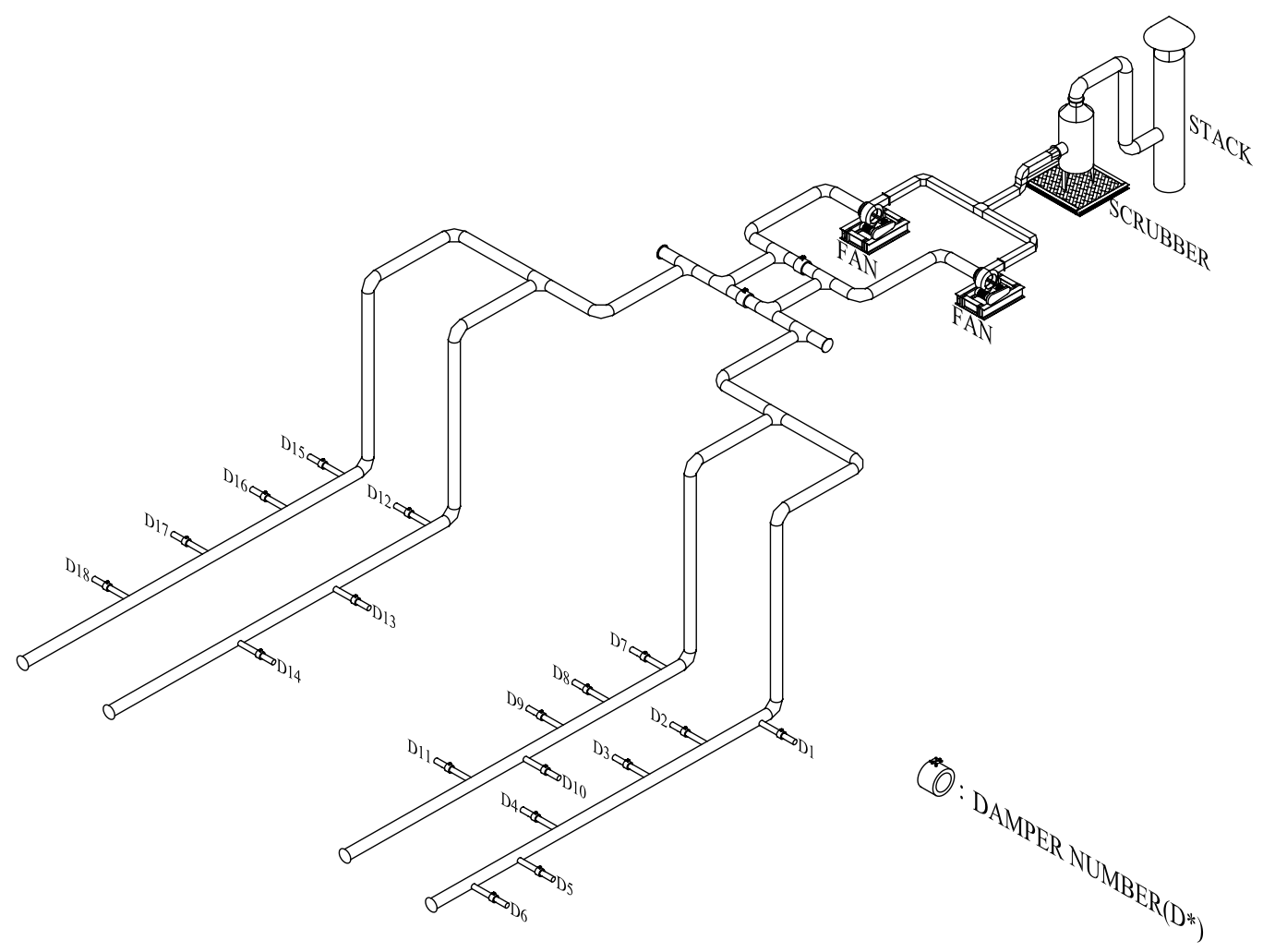

Fig. 4. Damper position of exhaust duct system. 


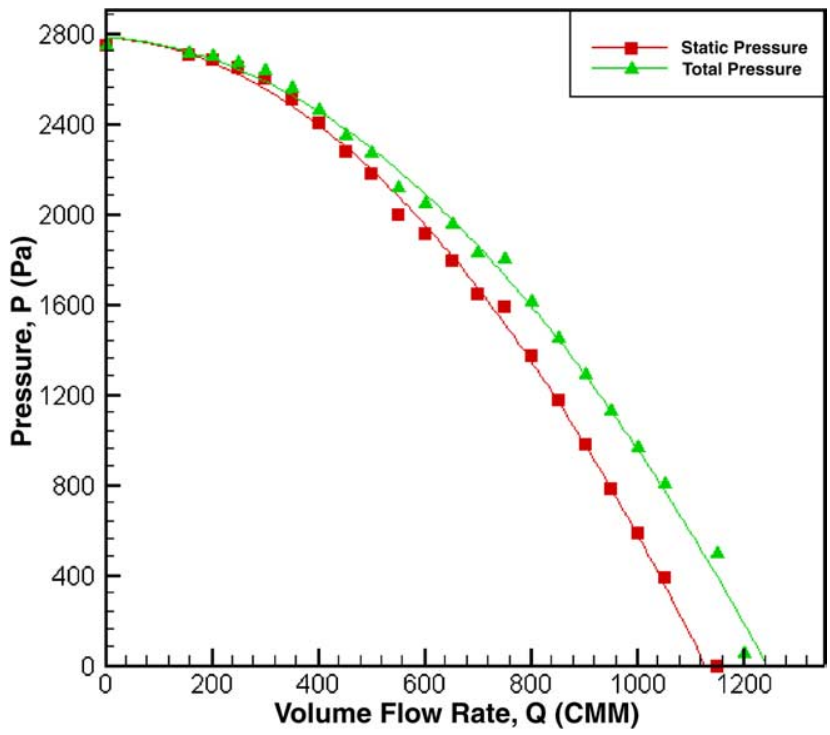

Fig. 5. Fan performance curves.

damper and the corresponding simulated damper angle as the exhaust duct system has been adjusted and balanced. Path no. 1 represents the combination of all ducts, branches and damper D1 between the fan and machine M1. Damper D1 stands for the damper used to adjust the flow rate on path 1 . Numbers of the rest paths are the same as described above. In this case, the total exhaust volume flow rate required by the total 11 machines is $800 \mathrm{CMM}$. From the fan performance curve, the fan total pressure is $1645 \mathrm{~Pa}$ and the fan volume flow rate is $800 \mathrm{CMM}$. Following the correction procedures devel- oped by this article, the total friction loss and total dynamic loss for ducts and branches and the dynamic loss created by the damper of various paths can be obtained. Noted that the total friction loss and total dynamic loss, which is the summation of both friction losses, for all paths should be $1645 \mathrm{~Pa}$ in order to meet the pressure balance. Then the dynamic friction loss of damper at each path is converted into the damper angle.

Table 3 shows the errors between the designed flow rate and simulated flow rate of various machines for iteration no. In the first iteration, as the dampers are fully open, the error tends to be greater. Machine M1 has the greatest error, with the error between designed and simulated values ranging up to $63.6 \%$. The paths having less friction loss in various paths have greater error in flow rate. In the second iteration correction the error between the designed flow rate and simulated flow rate significantly reduces. For machine M1, the error reduces to $8.17 \%$. When simulation is completed, the error of all machines can be kept within 5\%. It takes totally four iterations to reach the system pressure balance.

To compare the difference between the correction procedures developed by this article and the $3 \mathrm{C}$ method [8], simulations are demonstrated on two different correction procedures. Fig. 6 represents two different methods. The average error of flow rates of various paths is shown in Fig. 6. Referring to the first simulation results, it is found that, as both methods have not been corrected, the average error of flow rate of various paths is $40 \%$. The reason that both simulations generate the same error is because both simulation methods are based on the system simulation method brought up by

Table 1

Simulation parameters

\begin{tabular}{llll}
\hline Parameters & Value & Parameters & Value \\
\hline Air density $\left(\mathrm{kg} / \mathrm{m}^{3}\right)$ & 1.20 & Velocity lower limit $(\mathrm{m} / \mathrm{s})$ & 7.5 \\
Air viscosity $\left(\mathrm{m}^{2} / \mathrm{s}\right)$ & $1.54 \times 10^{-5}$ & Electricity unit cost $(\mathrm{NT} \$ / \mathrm{kW}-\mathrm{h})$ & 1.96 \\
Duct absolute roughness $(\mathrm{m})$ & $3 \times 10^{-4}$ & Yearly operation hours (h/year) & 8760 \\
Velocity upper limit $(\mathrm{m} / \mathrm{s})$ & 15 & Fan efficiency $(\%)$ & 70 \\
\hline
\end{tabular}

Table 2

Total loss and damper angle for all paths (damper control)

\begin{tabular}{lllll}
\hline Path number & $\begin{array}{l}\text { The total friction loss and the } \\
\text { total dynamic loss except dampers }(\mathrm{Pa})\end{array}$ & $\begin{array}{l}\text { Dynamic loss } \\
\text { of damper }(\mathrm{Pa})\end{array}$ & $\begin{array}{l}\text { Damper angle } \\
\left({ }^{\circ}\right)\end{array}$ \\
\hline 1 & 801.8 & 843.2 & 42 & $\begin{array}{l}\text { Path } \\
\text { description }\end{array}$ \\
2 & 959.4 & 685.6 & 24 & Fan-M1 \\
3 & 691.5 & 891.5 & 34 & Fan-M4 \\
4 & 817.3 & 827.7 & 39 & Fan-M6 \\
5 & 906.8 & 738.2 & 38 & Fan-M8 \\
6 & 1027.4 & 617.6 & 15 & Fan-M9 \\
7 & 789.3 & 855.7 & 40 & Fan-M11 \\
8 & 958.4 & 686.6 & 26 & Fan-M12 \\
9 & 830.8 & 814.2 & 46 & Fan-M14 \\
10 & 911.2 & 733.8 & 38 & Fan-M15 \\
11 & 1003.8 & 641.2 & 28 & Fan-M17 \\
\hline
\end{tabular}


Table 3

Damper control simulation results

\begin{tabular}{|c|c|c|c|c|c|}
\hline $\begin{array}{l}\text { Number of } \\
\text { iteration }\end{array}$ & $\begin{array}{l}\text { Machine } \\
\text { number }\end{array}$ & $\begin{array}{l}\text { Designed flow } \\
\text { rate }(\mathrm{CMM})\end{array}$ & $\begin{array}{l}\text { Simulated } \\
\text { flow rate }(\mathrm{CMM})\end{array}$ & Error $(\%)$ & $\begin{array}{l}\text { Damper angle } \\
\left({ }^{\circ}\right)\end{array}$ \\
\hline \multirow[t]{2}{*}{1} & M1 & 55 & 90.1 & 63.6 & 0 \\
\hline & M12 & 60 & 89.4 & 49.2 & 0 \\
\hline \multirow[t]{2}{*}{2} & M1 & 55 & 59.5 & 8.17 & 42 \\
\hline & M12 & 60 & 61.9 & 3.18 & 40 \\
\hline \multirow[t]{2}{*}{3} & M1 & 55 & 58.6 & 6.52 & 45 \\
\hline & M12 & 60 & 62.1 & 3.45 & 40 \\
\hline \multirow[t]{18}{*}{4} & M1 & 55 & 57.3 & 4.18 & 42 \\
\hline & M2 & 0 & 0.0 & 0.00 & 90 \\
\hline & M3 & 0 & 0.0 & 0.00 & 90 \\
\hline & M4 & 80 & 82.1 & 2.67 & 24 \\
\hline & M5 & 0 & 0.0 & 0.00 & 90 \\
\hline & M6 & 60 & 64.5 & 4.50 & 34 \\
\hline & M7 & 0 & 0.0 & 0.00 & 90 \\
\hline & M8 & 70 & 72.5 & 3.57 & 39 \\
\hline & M9 & 90 & 94.2 & 4.67 & 38 \\
\hline & M10 & 0 & 0.0 & 0.00 & 90 \\
\hline & M11 & 70 & 71.9 & 2.71 & 15 \\
\hline & M12 & 60 & 62.2 & 3.67 & 40 \\
\hline & M13 & 0 & 0.0 & 0.00 & 90 \\
\hline & M14 & 80 & 62.7 & 3.33 & 26 \\
\hline & M15 & 60 & 62.3 & 3.83 & 46 \\
\hline & M16 & 0 & 0.0 & 0.00 & 90 \\
\hline & M17 & 90 & 93.1 & 3.43 & 38 \\
\hline & M18 & 75 & 78.2 & 4.23 & 28 \\
\hline
\end{tabular}

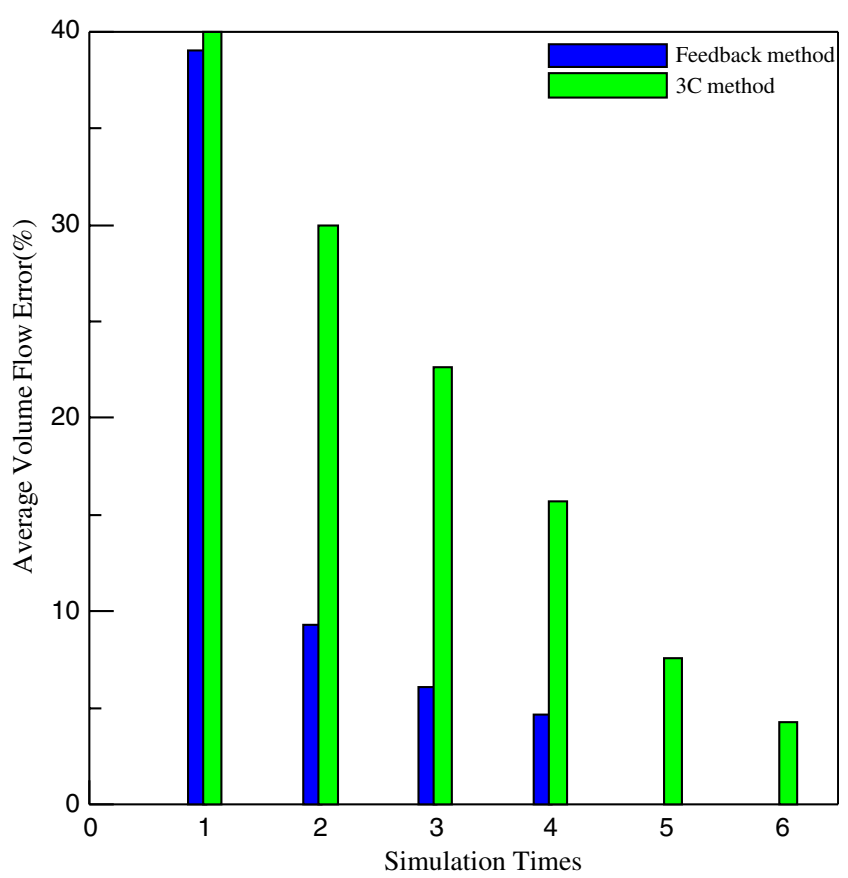

Fig. 6. Error of volume flow rate for feedback simulation and $3 \mathrm{C}$ method at each iteration (damper control).

Tsal et al. [7]. It is also due to the fact that in the first iteration all the dampers are fully open. Referring to the second simulation results, it is found that, if corrected with the correction procedures of present article, the average error of flow rate reduces to $9 \%$. If corrected with the correction sequences of the $3 \mathrm{C}$ method, the error keeps $30 \%$. By comparing both methods, it is found that the method suggested by this article takes only four simulation iterations to achieve system balance, while the $3 \mathrm{C}$ method requires six. The correction procedures established by this article can effectively reduce the number of iteration and save the time consuming. The cause of the difference is that the correction procedures established by the $3 \mathrm{C}$ method depend on many empirical rules and design experience. The presented feed simulation method develops an automatic correction procedure, which is based on the characteristics of flow distribution in the exhaust duct system. That is the fan operation point and the dynamic loss created by the dampers can be quickly obtained after iteration, which enables effective correction and reduces the simulation time. Based on the results shown in Table 3, quick system balance and adjustment can be conducted. The article uses a Pentium 4 computer. The simulation takes only $5 \mathrm{~min}$ from start to end, as opposed to 1-2 months spent conducting on-site exhaust balance and adjustment, significantly saving time and money.

\subsection{Fan speed control}

For the exhaust duct system, damper angle is usually adjusted to achieve system pressure balance. The 
purpose is to decrease the required flow rate by increasing system resistance. Though this method can achieve system balance, it increases the operation electrical cost. In order to achieve the two goals, system balance and energy saving, the fan speed control is an effective method. The article is to simulate by controlling the supply frequency to increase or decrease the fan speed. When the fan's speed at full load is 1440 RPM, set the speed to $1400 \mathrm{RPM}, 1350 \mathrm{RPM}, 1300 \mathrm{RPM}$, and $1250 \mathrm{RPM}$. When the speed is set at $1250 \mathrm{RPM}$ or below, the fan total pressure and flow rate are no longer enough to meet the requirements of the system. The operation condition 1250 RPM is thus set as the fan's minimum speed. According to the fan's perfor- mance curve, when the flow rate is $800 \mathrm{CMM}$ and speed $1250 \mathrm{RPM}$, the operation point pressure is $1085 \mathrm{~Pa}$. As stated above, the dynamic loss of all paths created by the damper can be obtained and can be converted to damper angle as shown in Table 4. Those can be used as the basis for the correction of the second iteration. Table 5 shows, during fan speed control simulation, the error between the designed flow rate and the simulated flow rate of various machines at each iteration. When conducting the third iteration, the error between the required and simulated flow rate of various ducts is within 5\%. From Tables 3-5, it is found that, through the fan speed control method, the damper angle of all paths is smaller than those obtained from damper

Table 4

Total loss and damper angle of all paths (fan speed control)

\begin{tabular}{|c|c|c|c|c|}
\hline Path number & $\begin{array}{l}\text { The total friction loss and } \\
\text { the total dynamic loss except dampers }(\mathrm{Pa})\end{array}$ & $\begin{array}{l}\text { Dynamic loss of } \\
\text { damper }(\mathrm{Pa})\end{array}$ & $\begin{array}{l}\text { Damper angle } \\
\left({ }^{\circ}\right)\end{array}$ & $\begin{array}{l}\text { Path } \\
\text { description }\end{array}$ \\
\hline 1 & 801.8 & 283.2 & 14 & Fan-M1 \\
\hline 2 & 959.4 & 125.6 & 7 & Fan-M4 \\
\hline 3 & 753.5 & 331.5 & 22 & Fan-M6 \\
\hline 4 & 817.3 & 267.7 & 13 & Fan-M8 \\
\hline 5 & 906.8 & 178.2 & 9 & Fan-M9 \\
\hline 6 & 1027.4 & 57.6 & 5 & Fan-M11 \\
\hline 7 & 789.3 & 295.7 & 14 & Fan-M12 \\
\hline 8 & 958.4 & 126.6 & 5 & Fan-M14 \\
\hline 9 & 830.8 & 254.2 & 14 & Fan-M15 \\
\hline 10 & 911.2 & 173.8 & 9 & Fan-M17 \\
\hline 11 & 1003.8 & 81.2 & 8 & Fan-M18 \\
\hline
\end{tabular}

Table 5

Fan speed control simulation results

\begin{tabular}{|c|c|c|c|c|c|}
\hline $\begin{array}{l}\text { Number of } \\
\text { iteration }\end{array}$ & $\begin{array}{l}\text { Machine } \\
\text { number }\end{array}$ & $\begin{array}{l}\text { Designed flow } \\
\text { rate }(\mathrm{CMM})\end{array}$ & $\begin{array}{l}\text { Simulated flow } \\
\text { rate }(\mathrm{CMM})\end{array}$ & $\begin{array}{l}\text { Error } \\
(\%)\end{array}$ & $\begin{array}{l}\text { Damper angle } \\
\left({ }^{\circ}\right)\end{array}$ \\
\hline 1 & $\begin{array}{l}\text { M1 } \\
\text { M12 }\end{array}$ & $\begin{array}{l}55 \\
60\end{array}$ & $\begin{array}{l}69.4 \\
74.3\end{array}$ & $\begin{array}{l}26.1 \\
23.9\end{array}$ & $\begin{array}{l}0 \\
0\end{array}$ \\
\hline 2 & $\begin{array}{l}\text { M1 } \\
\text { M12 }\end{array}$ & $\begin{array}{l}55 \\
60\end{array}$ & $\begin{array}{l}58.6 \\
62.1\end{array}$ & $\begin{array}{l}6.52 \\
3.45\end{array}$ & $\begin{array}{l}14 \\
14\end{array}$ \\
\hline 3 & $\begin{array}{l}\text { M1 } \\
\text { M2 } \\
\text { M3 } \\
\text { M4 } \\
\text { M5 } \\
\text { M6 } \\
\text { M7 } \\
\text { M8 } \\
\text { M9 } \\
\text { M10 } \\
\text { M11 } \\
\text { M12 } \\
\text { M13 } \\
\text { M14 } \\
\text { M15 } \\
\text { M16 } \\
\text { M17 } \\
\text { M18 }\end{array}$ & $\begin{array}{r}55 \\
0 \\
0 \\
80 \\
0 \\
60 \\
0 \\
70 \\
90 \\
0 \\
70 \\
60 \\
0 \\
80 \\
60 \\
0 \\
90 \\
75\end{array}$ & $\begin{array}{r}57.2 \\
0.0 \\
0.0 \\
82.8 \\
0.0 \\
62.9 \\
0.0 \\
72.2 \\
93.1 \\
0.0 \\
73.3 \\
62.1 \\
0.0 \\
81.9 \\
61.4 \\
0.0 \\
92.3 \\
78.6\end{array}$ & $\begin{array}{l}4.00 \\
0.00 \\
0.00 \\
3.50 \\
0.00 \\
4.89 \\
0.00 \\
3.14 \\
3.43 \\
0.00 \\
4.76 \\
3.50 \\
0.00 \\
2.33 \\
2.33 \\
0.00 \\
2.57 \\
4.80\end{array}$ & $\begin{array}{r}14 \\
90 \\
90 \\
7 \\
90 \\
22 \\
90 \\
13 \\
9 \\
90 \\
5 \\
14 \\
90 \\
5 \\
14 \\
90 \\
9 \\
8\end{array}$ \\
\hline
\end{tabular}


Table 6

Fan speed control operation cost

\begin{tabular}{lllllr}
\hline $\begin{array}{l}\text { Speed } \\
(\mathrm{RPM})\end{array}$ & $\begin{array}{l}\text { Horsepower consumed } \\
\text { by fan }(\mathrm{kW})\end{array}$ & $\begin{array}{l}\text { Electricity } \\
\text { price }(\mathrm{NT} / \mathrm{kW}-\mathrm{h})\end{array}$ & $\begin{array}{l}\text { Yearly operation } \\
\text { hours }(\mathrm{h})\end{array}$ & $\begin{array}{l}\text { Operation expense } \\
(\mathrm{NT} \$)\end{array}$ & $\begin{array}{l}\text { Energy } \\
\text { saved }(\%)\end{array}$ \\
\hline 1440 & 46.89 & 1.96 & 8760 & 805,082 & 0 \\
1400 & 43.09 & 1.96 & 8760 & 739,838 & 8.1 \\
1350 & 38.63 & 1.96 & 8760 & 663,261 & 17.6 \\
1300 & 34.50 & 1.96 & 8760 & 592,351 & 26.4 \\
1250 & 30.67 & 1.96 & 8760 & 526,591 & 34.7 \\
\hline
\end{tabular}

control method. This is because when the speed of the fan decreases, the total pressure and flow provided by the fan decrease as well. It is not necessary to increase extra damper resistance to achieve balance.

Table 6 shows the fan operation cost under different speeds. The operation electricity cost $E_{\mathrm{p}}$ is calculated as follows:

$E_{\mathrm{p}}=\frac{Q_{\mathrm{fan}} \cdot P_{\mathrm{fan}}}{\eta_{\mathrm{f}} \eta_{\mathrm{e}}} E_{\mathrm{c}} \cdot Y$

where $\eta_{\mathrm{f}}$ is fan efficiency, $\eta_{\mathrm{e}}$ motor efficiency, $E_{\mathrm{c}}$ electricity unit price and $Y$ system annual operation hours. When the speed is 1440 RPM, the annual operation expense is NT\$805,082. As fan speed reduces to 1250 RPM, there saves NT\$278,491 operation expense, a saving of $34.7 \%$.

The present paper provides a feedback simulation method to conduct on-site system balance, which is usually very complicated and time consuming in practical project. This method is also powerful when cooling or heating load distributions that change with time and use in thermal engineering system is considered. In addition to the pressure balance, load control for the thermal system must be rebalanced accordingly. The energy conservation strategies for the thermal system can also be obtained from the present method.

\section{Conclusion}

This article analyzes the exhaust duct system of a TFT-LCD factory with the feedback simulation method. With the help of the feedback simulation method, the time spent on balance and adjust can be effectively reduced. The proposed method allows the designer to conduct online simulation of the system over the computer during the design stage or as-build stage. The designer can find out at any time the defects of the design and the best operation strategy, which improves the design more flexible. Therefore, in the face of the challenge of lower cost and shorter time, use of the feedback simulation method in the design of the exhaust duct system can substantially improve the design efficiency, reduce work time and labor, which in turn raises the designer's competitiveness.

\section{Acknowledgements}

The authors would like to acknowledge the support of the National Science Council, ROC under project number NSC 92-2622-E-002-020-CC3. The effort of Dr. Chiang, Yuan Ching in the review of this manuscript is gratefully appreciated.

\section{References}

[1] ASHRAE, ASHRAE Handbook-Fundamentals, American Society of Heating, Refrigerating and Air-Conditioning Engineers, Atlanta (1997).

[2] ASHRAE, Duct fitting database, American Society of Heating, Refrigerating and Air-Conditioning Engineers, Atlanta (1994).

[3] ASHRAE, ASHRAE Handbook-Heating, Ventilating, and AirConditioning Applications, American Society of Heating, Refrigerating and Air-Conditioning Engineers, Atlanta (1995).

[4] R.J. Tsal, H.F. Behls, R. Mangel, T-method duct design, Part I: Optimization theory, ASHRAE Transactions 94 (2) (1988) 90-111.

[5] R.J. Tsal, H.F. Behls, R. Mangel, T-method duct design, Part II: Calculation procedure and economic analysis, ASHRAE Transactions 94 (2) (1988) 112-150.

[6] Y. Asiedu, R.W. Besant, P. Gu, HVAC duct system design using genetic algorithms, International Journal of HVAC \& R Research 6 (2) (2000) 149-173.

[7] R.J. Tsal, H.F. Behls, R. Mangel, T-method duct design Part III: Simulation, ASHRAE Transactions 96 (2) (1990) 3-31.

[8] W.L. Chen, C.C. Ting, H.R. Shiu, H.J. Chen, S.L. Chen, Application of $3 \mathrm{C}$ duct design method in semiconductor factory process exhaust systems, ASHRAE Transactions 106 (2) (2001) 210-220. 